to take part in the appointment of medical officers in industry, yet the method of appointment of members of the management-for the industrial medical officer is in this category-is a matter on which directors of firms must be consulted. Industry in this country is still largely run by private enterprise. It is no business of this Journal to predict the future of industry but, whatever its structure may be, one paragraph in the report must always apply: "It is necessary to dispose of the point of view that industry cannot afford a health service. Surely the opposite is the truth: industry cannot afford to be without a health service if efficiency and output are to be maintained.'

\section{FACTORY INSPECTION AND MEDICAL SCIENCE}

The Annual Report for 1943 of the Chief Inspector of Factories is a document of seventy pages of which seventeen are devoted to industrial medicine. Though this is undoubtedly an improvement on the four pages of 1940 , there can be little doubt that Dr. E. R. A. Merewether, with unrivalled sources of information available, could fill the whole volume with matter of the greatest value to medical science. The medical branch of the Factory Department includes some of the most distinguished doctors in the field of occupational medicine, and in the past many of them have made contributions of great value to science, for example Dr. Merewether's own work on asbestosis ${ }^{1}$; yet in the report no mention is made of the work of any of the medical inspectors, but they must have contributed to it in some form. The authoritative nature of the annual reports of hospitals such as Guy's and the Brompton can be compared with this brief document, containing no first-hand information, published by a government department with unique opportunities in an almost virgin field of medicine. The important facts relating to health collected by the Factory Department are of interest not only to works managers, personnel and labour managers, and the workers themselves, but are the urgent concern of doctors and scientists. So it is reasonable to suggest that in the future a separate medical report should be published each year and summarized in the Chief Inspector's Report.

On p. 21 the Chief Inspector refers to special investigations being carried out by his Department, and the first mentioned is luminizing. On p. 48 Dr. Merewether uses some of the scant space allotted to him to describe the results of the investigation, yet the amount of information he has been able to get into the space is valueless from a scientific point of view. There is neither a description of the conditions to which the workers were exposed, nor the clinical findings in those workers. Maybe the facts have been published elsewhere, but another striking feature of the report is that it is without references. We are told that as a result of the information, which is not published, further Orders have been made by the Minister of Labour. Doubt-

\footnotetext{
1 Effects of Asbestos Dust on the Lungs and Dust Suppression in the Asbestos Industry, 1930. H.M.S.O. Lond.; and Tubercle, 1933, 15, 69, 109, 152
}

less these are necessary and correct, but it would be more democratic to publish the facts which show their necessity.

Early work on chronic benzene poisoning by Santesson ${ }^{2}$ and Selling ${ }^{3}$ established the conception of a simple, constant clinical picture. This was an over-simplification based on insufficient human material. The work of Frank Hunter of Boston ${ }^{4}$ has made the problem of the relationship of leukaemia to benzene poisoning of the first importance. It is suggested in this report that a case occurred last year in England, yet no details are given of the exposure or the chemical findings; and no evidence is advanced that the man would not have died of leukaemia if he had never been exposed to benzene. Scarcity of human material may cause it to be many years before the relationship of benzene and leukaemia is fully understood, so that it would be a thousand pities if this case is not properly published forthwith.

The whole structure of medicine is at the present time in the melting pot and many reforms are necessary; but in this process all branches of medical thought are agreed that the freedom to publish scientific information must be ensured. It therefore follows that this freedom must be allowed to all medical inspectors and particularly to the senior medical inspector who prepares a report with such a wide circulation. Further, security must not be used in a rigid manner to prevent the dissemination of scientific knowledge; where it is truly involved we all agree that nothing should be published which might conceivably give useful information to the enemy. But now that the Ministry of Supply have published in a restricted form a paper on the early effects of exposure to trinitrotoluene, ${ }^{5}$ many will have had an opportunity of judging whether security can be considered a true reason for postponing the publication of this excellent piece of work.

\section{METHYL BROMIDE}

Methyl bromide is used in the chemical industry in the preparation of methylic compounds and for making colours from methylated tar. It has been extensively used in recent years as a fire-extinguisher, a refrigerant, a fumigant, and a delousing agent. It is an insecticide of great effectiveness and is capable of protecting a wide variety of foods, grain, plants and textiles. Entomologists favour its use in pest control because it leaves no smell or taste behind it, it is not explosive on mixture with air, it is highly toxic to insects in all stages of their development, it has a low absorption and high penetrating power, and is inexpensive. It is particularly effective in the extermination of lice, bed-bugs, and weevils.

It is a colourless, odourless gas at ordinary temperatures and pressures and is approximately three and a half times as heavy as air. As so often

\footnotetext{
2 Arch. Hyg., 1892, 31, 336.

3 Bull. Johns Hopk. Hosp., 1910, 21, 33; and Johns Hopk. Hosp. Rep., 1916, 17, 83 .

J. industr. Hyg., 1939, 21, 331. (1944). H.M.S.O. Lond.
Higgins, G. R. P., Stewart, Alice and Witts, L. J.
} 
happens, however, substances which are really effective against insects are also toxic to man, and on another page in this Journal Clarke, Roworth, and Holling give an account of poisoning occurring in four naval officers, two of whom died; and Wyers describes cases of poisoning which have arisen during the manufacture of the compound. The substance is used by the Royal Navy as a fire-extinguisher since its great density makes it very effective in the control of fire in high octane motor spirit. Its density and lack of smell, however, make it extremely dangerous should a leak occur in the firefighting apparatus in a small ship where the rooms are small with low roofs, possibly below water level. In actual fire-fighting, it is not dangerous since it is rapidly decomposed.

The toxic effects of methyl bromide have been known since 1901 when Jaquet ${ }^{1}$ reported one case with vertigo, weakness, and temporary visual disturbances following a brief exposure, and two cases with the same symptoms as well as asthenia and psychological disturbances following more prolonged exposure. Since that date some 42 cases have been reported, of which 12 were fatal and 23 recovered. Clarke, Roworth, and Holling now report that a concentration of 1 per cent. produces a marked irritation of the upper respiratory tract, headache, smarting of the eyes, abdominal discomfort, and numbness of the feet, which may last as a residual symptom for as long as four months. Death, when it occurs, usually results from pulmonary oedema. Lower concentrations, while producing these symptoms in milder degree, also cause delayed symptoms, visual disturbances, amblyopia, drowsiness and fits. Convalescence is characterized by depression and sleeplessness.

Besides these general symptoms, local contact with liquid methyl bromide produces severe characteristic vesicular burns. These are important in industry and many workers making the substance have these blisters on their hands. Also, while fire-fighting with a methyl bromide fire-extinguisher, some of the liquid may get on the man's clothing, which it will readily penetrate. On a previous page Butler, Perry, and Williams have described the cases of two soldiers who received burns in this manner after the liquid had penetrated army boots and anklets.

During the last year cases of poisoning in industry were reported from America by Heimann ${ }^{2}$ and De Jong $^{3}$; none of the cases was severe but they demonstrated the symptoms described above as typical of the condition. Now we have an account by Wyers of a further nine cases. Watrous 4 investigated, during a two-week period, 90 men working in the filling and sealing room at a factory. $\mathrm{He}$ found the concentration of methyl bromide

1 Jaquet, A. (1901). Dtsch. Arch. klin. Med., 71, 370.

2 Heimann, H. (1944). Industr. Bull., 23, 103.

3 De Jong, R.N.(1944). J. Amer. med. Ass., 125, 702. in the atmosphere to be 35 parts per million, a concentration usually considered to be well within the limit of safety; yet 31 of the workers showed mild toxic effects. Anorexia, nausea and vomiting occurred most frequently, but other symptoms included headache, vertigo, difficulty in focusing the eyes, lethargy, muscular pains, faintness, and dimness of vision.

Sayers, Yant, Thomas, and Berger ${ }^{5}$ have worked out the toxic effect of the substance in animals, and further work has been carried out recently by Irish, Adams, Spencer, and Rowe. ${ }^{6}$ These workers have shown methyl bromide to be by far the most toxic of the four organic halides-methyl bromide, methyl chloride, ethyl bromide, and ethyl chloride. Animals which are exposed to lethal doses of the poison die with pulmonary congestion and oedema, or, if they survive long enough, with confluent broncho-pneumonia. Lower concentrations cause excitability and muscular tremors followed by a paralysis from which the animals recover completely when removed from exposure to the gas. Animals killed after these exposures showed at necropsy degeneration of the heart muscle, congestion and haemorrhage of the lungs, kidneys, spleen, and liver. There was sometimes also congestion of the brain and meninges.

It is evident, therefore, that methyl bromide is a highly toxic substance and adequate protective measures must be devised to give protection from it. This certainly presents some difficulties. In low concentrations the gas is odourless, and it is able to pass in a matter of a quarter of an hour through the ordinary service gas mask which, therefore, gives little protection. Clarke, Roworth, and Holling suggest that some substance with a smell be added to methyl bromide in fire-extinguishers to draw attention to any leak; this is an excellent suggestion provided all existing containers are withdrawn and replaced by the new variety, otherwise a sense of false security might arise. Fire-fighters who have to use these extinguishers should be warned against spilling the substance and instructed that any clothing which is wetted by it must be removed immediately. When it is used as a fumigant, the trucks, ships, storehouses, barns, or other buildings must be thoroughly ventilated on the completion of the process. Where the substance is used in industry, the most important protective measure is adequate ventilation. Methyl bromide is a heavy gas and, therefore, can readily be extracted by exhaust ventilation through the floor of the workshop. As Wyers says ' hygiene of the place of work is of much greater importance than treatment' where so little can be done once symptoms are established.

\footnotetext{
5 Sayers, R. R., Yant, W. P., Thomas, B. G. H., and Berger, L. B. (1929). U.S. Treasury Dept., Publ. Hith. Serv. Bull., No. 185. (1940). J. industr. Hyg., 22, 218; (1941) Ibid., 23, 408.
} 